\title{
A educação e o auanço da nova (ou extrema?) direita no Brasil: entrevista com Gaudêncio Frigotto
}

\author{
The education and rise of the new (or extreme?) right in Brazil: \\ interview with Gaudêncio Frigotto
}

\section{La educación y el avance de la nueva (o extrema?) derecha en Brasil: entrevista con Gaudêncio Frigotto}

\section{Jorge Fernando Hermida ${ }^{1}$}

Universidade Federal da Paraíba, Programa de Pós-graduação em Educação e Mestrado Profissional em Gestão em Organizações Aprendentes, Professor.

https://orcid.org/0000-0003-1963-4639

\section{Jailton Lira²}

Universidade Federal de Alagoas, Professor Adjunto. https://orcid.org/0000-0002-3534-0553

Resumo: A presente entrevista com o Professor Gaudêncio Frigotto tem como tema central os acontecimentos sociais, políticos e educacionais mais relevantes dos últimos tempos: o colapso da democracia liberal, o golpe jurídico-midiático-parlamentar, o avanço da extrema-direita e o processo de desconstrução de históricas conquistas sociais e políticas - focando, em particular, nas políticas educacionais. Gaudêncio Frigotto é Professor titular de Economia Política e Educação na Universidade Federal Fluminense (aposentado). Atualmente é Professor do Programa de Pós-graduação em Políticas Públicas e Formação Humana da Universidade do Estado de Rio de Janeiro (UERJ). 0 Professor Frigotto sempre conseguiu conciliar vida acadêmica e militância social, tornando-se, com o passar do tempo, um dos nomes mais representativos da defesa da educação pública, gratuita, de qualidade e socialmente referenciada. No ano de 2015 foi agraciado com o prêmio Luta pela Terra - 30 anos do MST pelo Movimento dos Trabalhadores sem Terra.

Palavras-chave: Educação. Políticas educacionais. Democracia liberal. Extrema direita. Capitalismo.

Abstract: The present interview with Professor Gaudêncio Frigotto has as its central theme the most relevant social, political and educational events of recent times: the collapse of liberal democracy, the

Pós-doutor em Sociologia da Educação pela Universidad de Salamanca (España); Doutor em Filosofia e História da Educação pela Universidade de Campinas

2 Doutor em Educação pela Universidade Federal da Paraiba; Mestre em Educação pela Universidade Federal de Alagoas. 
Legal-Media-parliamentary coup, the rise of the extreme right and the process of deconstruction of historical, social and political achievements - focusing, in particular, on educational policies. Gaudêncio Frigotto is a professor in Political Economy and Education at Universidade Federal Fluminense (retired). He is currently a professor at the Postgraduate Program in Public Policies and Human Development at the University of Rio de Janeiro (UERJ). Professor Frigotto has always managed to combine academic life and social engagement, becoming, over time, one of the most representative names in defense of public and free of charge education, with good quality and socially recognized. In 2015, he was awarded with the prize Luta pela Terra - 30 anos do MST (Fight for the Land - 30 years of the MST) by the Brazilian Landless Workers Movement.

Keywords: Education. Educational policies. Liberal democracy. Extreme right. Capitalism.

Resumen: Esta entrevista con el profesor Gaudencio Frigotto tiene como tema central los eventos sociales, políticos y educativos más relevantes de los últimos tiempos: el colapso de la democracia liberal, el golpe legal-mediático-parlamentario, el avance de la extrema derecha y el proceso de deconstrucción de históricas conquistas sociales y políticas, centrándose en particular en las políticas educativas. Gaudêncio Frigotto es catedrático de Economía Política y Educación en la Universidad Federal Fluminense (jubilado). Actualmente es profesor del Programa de Postgrado en Políticas Públicas y Formación Humana de la Universidad Estatal de Río de Janeiro (UERJ). El profesor Frigotto siempre consiguió conciliar vida académica y militancia social, convirtiéndose, con el pasar del tiempo, en uno de los nombres más representativos de la defensa de la educación pública, gratuita, de calidad y socialmente referenciada. En 2015, recibió el premio Lucha por la Tierra: 30 años del MST, del Movimiento de los Trabajadores sin Tierra.

Palavras clave: Educación. Politicas educativas. Democracia liberal. Extrema derecha. Capitalismo.

Recebido em 11 de outubro de 2019 Aceito em 6 de abril de 2020 Publicado em 10 de junho de 2020

Jorge Fernando Hermida (JPH): Quem é Gaudêncio Frigotto? Como se (auto)definiria? Gaudêncio Frigotto (GF): Camponês de origem, sendo o sétimo filho de uma família de nove. Nossos pais, pequenos agricultores do interior do Rio Grande do Sul, nos criaram com enormes sacrificios e com extraordinária dignidade. Do campo trago minhas raízes e a ele estou ligado na militância, especialmente ao Movimento dos Trabalhadores Sem Terra (MST) desde seu surgimento. Nesse sentido, as duas graduações (Filosofia e Pedagogia) e o Mestrado e o Doutorado em Educação fazem parte da formação profissional, mas o melhor título que dá sentido à minha prática acadêmica e política é o de amigo da terra, concedido pela Escola Florestan Fernandes. Ele traduz, talvez, o que Florestan Fernandes define como 
sendo o papel do "intelectual militante" - a busca de rigor no processo de formação e de pesquisa, mas com vínculo ativo com as lutas da classe trabalhadora do campo e da cidade. Comungo da tese do historiador Eric Hobsbawm de que os seres humanos não foram criados para viver sob o capitalismo.

Jailton De Souza Lira (JSL): Intitulamos o dossiê de "Politicas educacionais e o avanço da Nova (ou extrema?) Direita". Para Castells (2018), a emergência da nova ou extrema direita está diretamente associada ao colapso da democracia liberal e suas formas de fazer política. Queremos escutar seus comentários sobre essa conjuntura atual.

GF: Certamente a democracia liberal está em crise. 0 que explica pela raiz essa crise não é, sobretudo, o modo de fazer política, mas o que o conduziu. 0 colapso da democracia liberal advém, na perspectiva das análises de Eric Hobsbawm, István Mészáros, David Harvey, dentre outros autores, do modo mediante o qual o capitalismo enfrenta a crise estrutural do sistema capital. Uma crise, como nos indica Mészáros, que é universal, no sentido que atinge todas as esferas da vida; global, porque é sistêmica e não mais localizada apenas em regiões, mas mundial; e não é mais cíclica, mas permanente.

A emergência de governos de extrema direita em diferentes partes do mundo resulta do que Marx e Engels já identificavam, em meados século XIX, como sendo a contradição fundamental do capital: a capacidade exponencial de potenciar forças produtivas e de concentrar propriedade e riqueza e a incapacidade crescente de socializar ou dar acesso à produção. Como nos indica Hobsbawm, o problema não é a produção, mas a distribuição. $E$ isso só se faz mediante políticas da esfera pública. 0 que menos conta hoje na produção, como sublinha esse autor, é o fator humano. 0 capital apropriou-se da ciência privadamente, quando na verdade ela é um bem comum da humanidade, assim como o é a terra, a água, os bens minerais, etc. Vivemos, então, num tempo histórico em que o capital nega, ao mesmo tempo, a maioria da classe trabalhadora que tenha propriedade como valor de uso e, também, nega o emprego, pois precisa cada vez menos de trabalhadores em todas as esferas da produção.

Em uma situação como esta ou se criam empregos na esfera pública ou se utilizará a violência do Estado, eliminando, de diferentes formas, forças produtivas, em particular o trabalho humano. 0 Brasil é hoje, como indica numa recente entrevista Michael Löwy, o país que tem o governo de extrema direita com características mais claras de neofascismo. Um governo que reúne a estupidez, a insensatez e a insanidade. A primeira, pelo fundamentalismo econômico com a política de privatizar tudo e entregar tudo ao mercado e ao capital; a segunda se expressa pelo fundamentalismo político, que trata os adversários, os movimentos sociais e políticos, que lutam por direitos e pensamento divergente, como inimigos a serem 
abatidos; e a insanidade, que resulta das duas anteriores, que é o de armar a população e de utilizar a violência do Estado como estratégia contra as populações pobres, em especial jovens e negros. A insanidade também engloba o fundamentalismo religioso, que submete a esfera pública ao mundo privado da religião e a ciência, à crença.

A crise da democracia liberal, portanto, tem sua raiz fundamental na forma como o capital enfrenta a sua crise estrutural, eliminando direitos, retomando políticas de expropriação e contendo a pobreza e o desespero que ela produz, pela violência.

JPH: Depois de se apropriar do governo por meio de um golpe jurídicomidiático-parlamentar, Michel Temer iniciou um processo de desconstrução de históricas conquistas sociais. Ele implementou uma agenda de reformas na educação, na legislação trabalhista e em algumas empresas estatais. Temer completou o seu mandato presidencial com baixa popularidade. Dentre as principais medidas implementadas que afetam diretamente a educação, destacam-se: a contrarreforma do Ensino Médio, a Emenda Constitucional n. 95 e a Base Nacional Comum Curricular. Qual é o legado que o Governo Michel Temer deixou para a educação nacional?

GF: Esta questão liga-se à anterior. Um olhar histórico sobre nossa sociedade nos indica que ela produziu uma classe dominante que tem um DNA colonizador, escravocrata e que optou não por construir uma nação autônoma e soberana, mas um país de capitalismo dependente. Este se expressa pela abismal concentração de propriedade la terra é um exemplo emblemático), de capital e riqueza, e manutenção e ampliação da pobreza e miséria. Uma classe dominante que sempre se manteve antinacional, antipovo e antieducação pública, universal, gratuita e de qualidade para a maioria da classe trabalhadora.

Isso explica o fato de que todas as vezes em que há conquistas da classe trabalhadora em seus direitos sociais e se esboça força social e política para mudanças estruturais, ainda que dentro da (des)ordem capitalista, efetiva-se uma ditadura ou um golpe de diferentes proporções. 0 golpe de estado de 2016 expressa essa constância em defesa do latifúndio, da concentração de renda e de capital e, sobretudo, do capital financeiro. 0 legado trágico do golpe do Governo Temer, como testa de ferro ou barriga de aluguel do bloco de poder que governou o Brasil, em especial nos dois mandatos de Fernando Henrique Cardoso, é duplo. Primeiro, completou com mais radicalidade as políticas neoliberais, no que a Emenda Constitucional $n$. 95 é emblemática e que se completa mediante a contrarreforma trabalhista e do Ensino Médio. Esta liquida com concepção de Educação Básica e escancara a perspectiva mercantil no conteúdo, no método e na forma de educar, além de abrir esse nível ao mercado da educação. Mas o segundo legado trágico é ter como resultado não esperado a eleição de um bloco de poder de extrema direita. Esse é o legado, como sublinhei anteriormente, que 
se pauta pela tríade da estupidez, insensatez e insanidade humana. Uma situação em que o presente e o futuro de gerações estão interditados.

JSL: Quando à época de sua aprovação, o Plano Nacional de Educação de 2014 representava a possibilidade concreta de melhoria da qualidade educacional a partir dos elementos financeiros previstos, a exemplo da utilização dos recursos provenientes da exploração das jazidas minerais do Pré-sal e da ampliação dos investimentos públicos em educação, de modo que, até o fim da década, o País alcançasse o percentual de investimentos de 10\% na área. Com a mudança drástica das condições econômicas, políticas e sociais desde então, como é possível reorientar as prioridades e, por tabela, os investimentos em educação?

GF: 0 legado do Governo Michel Temer, com suas contrarreformas anteriormente sinalizadas, inviabilizou quase por completo não só a meta do financiamento, mas o Plano Nacional em seu conjunto. 0 atual governo completa a liquidação com a retirada absurda de recursos do Ministério da Educação e com sua política obscurantista anticiência e anticonhecimento. 0 que se interdita são as bases da cidadania política para a maioria da juventude que frequenta a escola pública e a sua condenação ao trabalho precário ou ao subemprego e desemprego. A política de privatizar tudo do pouco que restava - o Pré-sal já o foi, agora são mais 20 estatais, incluindo a Petrobras em pauta, e nenhuma perspectiva se abre, a não ser a luta política para reverter tal situação. Essa é uma agenda permanente, não apenas por conta do desmanche da educação e da saúde pública, mas pela ideologia que pauta o atual governo.

$\mathrm{JPH}$ : Como o senhor analisa a relação entre o capitalismo implementado por governos de extrema direita (como é o caso do atual governo brasileiro) e a democracia? São compatíveis?

GF: Num belíssimo livro, Democracia contra o capitalismo: a renovação do materialismo histórico, Ellen M. Wood (2010) mostra que a democracia, no seu sentido dado pelos gregos de soberania popular, é impossivel sob o capitalismo, mas a luta democrática é fundamental para garantir direitos e na construção da travessia de superação do sistema capitalista de relações sociais. No Brasil, desde o golpe de 2016, vivemos, apenas formalmente, um regime de frágil democracia. Com o atual governo, o Estado democrático de direito derivou para um estado de exceção dentro do qual a democracia definha. Na estratégia de confronto permanente e de ódio aos adversários e ao pensamento divergente, cultivado pelo núcleo central do atual governo, resta pouco da democracia formal. Parece que a agenda política do governo se pauta pela ideologia da pós-verdade que, em termos epistemológicos, é um retorno ao relativismo absoluto para o qual a verdade sobre os fatos e acontecimentos, 
inclusive em relação à ciência, é o que é para cada um. Substitui o conhecimento, que exige parcimonioso trabalho de reunir fontes, dados e análise, pela convicção.

0 lema dessa ideologia é: não tenho provas, mas tenho convicção e é esta que vale. Cada dia temos exemplos disso que partem do presidente atual e de seu núcleo devoto. Em relação às queimadas, ele tem a convicção de que são obra de Organizações não Governamentais (ONGs) estrangeiras que querem debilitar e desestabilizar o seu governo. Da mesma forma, afirma ter certeza de que a pesquisa de décadas do Instituto Nacional de Pesquisas Espaciais (INPE) sobre desmatamento é falsa.

JSL: Com discursos antiestablishment ancorados na ideologia ultraliberal e de extrema direita, novos atores políticos conseguiram chegar ao poder por meio de processos eleitorais. No entanto, a história nos ensina que esse tipo de discurso antiestablishment era característico dos partidos de esquerda, socialistas e comunistas. 0 que aconteceu que os polos ideológicos se inverteram? Antiestablishment são agora os partidos de extrema direita? 0 que houve de errado?

GF: No plano da dialética materialista histórica, uma mesma postura pode ter sinais opostos. 0 que lhes dá sentido é o conteúdo político, social e humano que engendra. № caso da esquerda, ou mais apropriadamente das esquerdas, os erros são muitos. 0 mais grave é o de não ter politizado suas bases para efetivar reformas estruturais, dentro da ordem capitalista, mas contra esse establishment. Em nossa história, essas reformas foram postergadas ou interrompidas por ditaduras e golpes, como sinalizei anteriormente. Mesmo sendo contra o sistema capitalista, a esquerda revolucionária fica impotente de, na prática, construir forças para um projeto socialista.

A postura antiestablishment do atual bloco de poder é posta. Usa a retórica de ser contra a velha politica, mas mostra-se cada vez mais fazendo-a, e em grau maior, porque dentro de um Estado de exceção. Na verdade, o que o governo quer é eliminar a política como a entende Jacques Rancière: luta dos que estão fora dos direitos para colocá-los na agenda do debate democrático. 0 que estamos vivendo no Brasil, tomando como referência a análise que Andrew Korybko expõe em seu livro Guerras hibridas - das revoluções coloridas aos golpes (2018), é uma ditadura híbrida. Ou seja, um governo ultra-autoritário e anti-instituições democráticas e científicas, eleito pela engenharia midiática das fakes. Por isso é um governo antipolítica e que aprofunda a violência das relações capitalistas numa das sociedades mais desiguais do mundo.

$\mathrm{JPH}:$ Os movimentos sindicais e sociais tiveram grande participação na redemocratização do País e, desde a promulgação da Constituição Federal de 1988, 
avançaram suas pautas em defensa dos Direitos Humanos, do meio ambiente, das mulheres, dos LGBTs, dos negros, dentre outros movimentos que lutam por mais igualdade no mundo. Aparentemente, caminhávamos para uma sociedade mais democrática, solidária e inclusiva. Contrastando com isso, tivemos o avanço (silencioso?) de grupos reacionários que mais uma vez se utilizam da velha bandeira "Deus, familia e propriedade". Vivenciamos um momento de extremo retrocesso no que se refere às pautas trabalhistas e sociais, sobretudo as educacionais e ambientais, mas, também, com o aumento da violência contra as mulheres e os LGBTs. Como chegamos a esse retrocesso civilizatório?

GF: A resposta a essa questão tem seu fundamento maior no que analisei, ainda que brevemente, na questão dois. 0 retrocesso nas pautas trabalhista, da previdência, da educação, ambientais e da liquidação da esfera pública é uma medida para manter as taxas de lucro no contexto da crise de estrutura do sistema capitalista. Por isso, a manutenção do sistema capitalista cada vez mais dependerá do uso da violência. Daí o ressurgimento de partidos de extrema direita que seguem, num outro tempo histórico e com instrumentos de violência diversos, a agenda dos governos nazifascistas.

Com efeito, na gênese do nazismo estava a disseminação do ódio aos ciganos, depois aos estrangeiros e quem não tivesse olho azul (raça pura) e, por fim, de quem fosse suspeito de ser comunista. As milícias da gênese do sistema nazista tornaram-se aparato do estado nazista. A mesma trilha pautou Mussolini no fascismo na ltália. Hoje isso se traduz pelo ódio aos pobres, pelo racismo e por questões de ordem cultural e moral em relação à violência contra as mulheres e, em especial, contra a condição de gênero pelo ódio e ataque aos grupos LGBTs. Cada dia se explicita mais o que Eric Hobsbawm sinalizava depois da derrocada do socialismo realmente existente. Para ele, inaugurou-se um tempo em que "o que hoje é comum à humanidade é a negação do que a espécie humana tem em comum."

JSL: As suas últimas publicações nos conduzem para algumas constatações. Dentre as mais relevantes, temos aquela que diz que a educação brasileira vivencia um momento controverso, que vai além dos problemas estruturais e de suas proposituras didáticas. A educação em todos os seus níveis se tornou alvo de disputas, e o atual processo de desconstrução das escolas e universidades públicas se apoia em três tipos de fundamentos: o religioso (os evangélicos e seu combate às ideologias de gênero), o político (a extrema direita, o militarismo, o fascismo) e o econômico (ultraliberalismo, privatização, estado mínimo). Parece-nos uma visão apocalíptica. No entanto, precisamos encontrar uma saída. 0 que pode ser feito?

GF: No plano racional é difícil ser otimista. Por isso reiterei, numa resposta anterior, o sentido que engendram esses fundamentalismos. Do que colho de debates e de leituras 
de cientistas sociais, psicanalistas, intelectuais ligados à cultura e à arte e, inclusive, teólogos que não usam Deus como mercadoria, entendo que esses fundamentalismos se potenciam e se constituem na esfinge a ser entendida e enfrentada politicamente. Lembro aqui de duas crônicas de Luis Fernando Verissimo no contexto das manifestações de 2014 e 2015. A primeira, 0 alarme (20 de fevereiro de 2014), na qual se pergunta (e nos interpela) se os judeus, grandes cientistas e integrados na sociedade alemã, não se deram conta dos sinais existentes da ideologia e das práticas nazistas ou se quando perceberam já era tarde. A segunda, 0 ódio (25 de junho de 2015), em referência ao linchamento humano que se efetivou, com o apoio da mídia empresarial, da então presidente Dilma Rousseff e dos petralhas (referência ao PT), hoje estendida ao pensamento de e ao que denominam de marxismo cultural e ideologia de gênero. Mas também ódio aos mortadelas, referência aos pobres e às políticas de distribuição de renda, assistenciais e de inclusão na Rede Federal de Educação, Ciência e Tecnologia e nas universidades públicas.

Por isso, mesmo não me eximindo de contradições, não entendo que seja uma postura apocalíptica. 0 que tenho buscado nos escritos e em conferências e debates é sinalizar que só a luta política e o enfrentamento da pedagogia do medo podem derrotar a esfinge que nos ameaça. Nesse sentido, também não tenho me furtado de socializar o que tenho aprendido em permanente interlocução com movimentos sociais do campo e da cidade e colegas pesquisadores das pautas que são cruciais e que exigem do setor de esquerda, em suas posições diversas e sem anulá-las, uma unidade substancial, profunda e inabalável numa agenda de ações práticas sobre as quais nenhuma entidade de esquerda ou mesmo que defende direitos democráticos poderia se opor. Como aprendemos em Marx e Engels, as ideias por si mesmas nada mudam, são os homens e mulheres, em luta e na ação prática, que alteram o curso da história. Creio que o que me baliza, no contexto regressivo em todos os campos que dizem respeito à vida humana, é o que Antonio Gramsci situa na relação pessimismo da razão e otimismo da vontade. Mas buscarei ver em textos recentes em que possa dar uma interpretação de uma análise apocalíptica.

JPH: 0 Ministério da Educação apresentou recentemente o Projeto Future-se, que estimula ainda mais a mercantilização da educação brasileira, desresponsabiliza o Estado do financiamento das universidades e compromete a autonomia destas. Quais as alternativas possíveis de resistência a mais essa ação do mercado contra a educação pública? 0 que esperar de um projeto que mascara a privatização e retira a autonomia das universidades e institutos federais?

GF: Essas medidas corporificam que, de fato, estamos num estado de exceção em que a Constituição de 1988 é modificada ou ignorada. Portanto, um governo autoritário que governa dentro do que define de ditadura híbrida. 0 que engendra um poder destrutivo mais 
profundo do que o que vivenciamos na ditadura empresarial militar de 1964 e nos governos de implantação das políticas neoliberais na década de 1990. A extrema direita tem o apoio do capital financeiro, de empresários, de denominações religiosas, mormente neopentecostais, e de parte de uma população manipulada sob o moralismo dessas denominações ou da mídia empresarial. Talvez o que melhor define o papel da mídia empresarial brasileira hoje é o que sinalizam Joseph Pulitzer e Karl Kraus (apud HOBSBAWN, 2013, p. 162). 0 primeiro, quando indica que, "com o tempo, uma imprensa cínica, mercenária, demagógica e corrupta formará um público tão vil como ela mesma." 0 segundo, ao observar o papel da grande mídia no contexto da Primeira Guerra Mundial, indicava que a imprensa não só expressava a corrupção da época, mas era ela própria a grande corruptora, simplesmente pelo "confisco dos valores através da palavra."

Assim, o Future-se pode ser traduzido por frature-se, privatize-se. Uma medida coerente com o apoio unidimensional ao mercado global do ensino, liquidação da pesquisa científica e de núcleos que cultivam valores democráticos e, em minoria, que produzem pensamento crítico. 0 ataque às disciplinas de filosofia, história, sociologia arte, entre outras, define um governo que se pauta no obscurantismo e na doutrina do pensamento único ultraconservador na economia, e de extrema direita no plano social, cultural e político. Um cenário em que os institutos federais e as universidades públicas deveriam estar em vigília permanente, mostrando aos jovens que é seu futuro que está sendo obstruído. Penso que se a juventude (secundaristas e universitários) perceber que seu futuro só existirá se construído no presente, nas ruas e praças, tomará outro sentido político. Assim, creio, reside a possibilidade maior de enfrentar e vencer a esfinge.

JSL: Um termômetro importante do crescimento da extrema direita, sem dúvida, é a ampliação de iniciativas de caráter fascista como a proposição de Projetos de Lei do tipo "Escola Sem Partido" - do qual o senhor é um dos mais importantes críticos - e a "caça" de "professores comunistas" nas universidades (como se as universidades estivessem repletas de comunistas, quando sabemos que dentro das universidades eles são poucos e sem espaço quanto na sociedade como um todo). Como é possível superar esse ambiente de perseguição política e ideológica à categoria docente no Brasil? Quais as melhores estratégias de enfrentamento a esse violento e absurdo ataque à democracia?

GF: Norberto Bobbio (1994) caracteriza os governos de extrema direita como os que seguem a doutrina nazista e fascista. E é dentro desse quadro que o pensador Michael Löwy caracteriza o núcleo ideológico do atual governo. "Vejo a figura de Jair Bolsonaro e de boa parte de seu governo com traços fascistas de autoritarismo, com essa ideia de que precisamos 'exterminar' o inimigo. 0 inimigo sendo a esquerda, as feministas, os indígenas, o MST, etc. Esse ódio ao 'comunismo', que para ele é toda a esquerda, é uma característica 
do fascismo - assim como a ideia de que a única solução é a repressão. Temos muitos governos de extrema direita no mundo hoje em dia, infelizmente, como [Donald] Trump, nos Estados Unidos, [Viktor] Orbán, na Hungria, [Narendra] Modi, na Índia. Mas o que tem mais traços semifascistas, ou neofascistas, é o de Jair Bolsonaro." (PAIXÃO, 2019).

Esses traços se manifestam justamente pela reiteração do ódio àquele que pensa diferente no plano político e no campo do conhecimento. Daí a criminalização da esquerda, dos socialistas e do pensamento crítico. lsso se expressa pelo que denominam de marxismo cultural (uma expressão genérica e desprovida de sentido). Do mesmo modo, a questão da ideologia de gênero e de que os professores doutrinam seus alunos. 0 combate a essas posturas implica não cair na armadilha do medo. 0 medo é uma forma de neutralizar a ação política. Mas, individualmente, todos têm medo, e, por isso, a sua superação só pode ocorrer na organização e ação coletivas.

Um exemplo de como se pode enfrentar coletivamente a estratégia da ameaça, da denúncia de professores ou pesquisadores que usam determinada literatura ou fazem determinadas análises que são científica e politicamente fundamentadas, como é o caso do racismo entre nós, da criminalização dos movimentos sociais e das análises sobre gênero nos foi dado pelo colega Alessio Surian, Professor da Universidade de Pádua, Itália. Comentando o absurdo da tentativa do Governo Bolsonaro de cassar o título dado a Paulo Freire de Patrono da Educação brasileira, Surian relatou que um partido neofascista na Alemanha, recentemente, usava a estratégia da denúncia a professores que utilizavam determinados autores em suas aulas e ameaçava de prisão. Os colegas, solidários, fizeram um abaixo-assinado dizendo que faziam uso daqueles autores e materiais e que não precisavam que alguém os denunciasse, eles estavam se denunciando e que, portanto, podiam prender a todos.

JPH: Alguns veículos de comunicação noticiaram que o Movimento Escola Sem Partido (EsP), liderado por Miguel Nagib, anunciou o encerramento das atividades a partir do mês de agosto, alegando falta de apoio por parte do Presidente Jair Bolsonaro. Esse "recuo" significa um enfraquecimento do movimento diante da sociedade civil e suas articulações políticas ou significa a organização de novas estratégias da extrema direita?

GF: Até onde se possa apreender, o anúncio do encerramento indica as duas coisas. Certamente não a desistência. As derrotas no Supremo das iniciativas dos dois dos filhos de Bolsonaro de apresentar projetos de lei para transformar o movimento na "lei da mordaça" foram um balde de água fria daqueles que, em alguns estados e municípios, os seguiram com propostas similares ou iguais. Também a forte mobilização de intelectuais, de alguns partidos políticos, sindicatos e movimentos sociais na explicitação à sociedade do absurdo das teses do partido ideológico do movimento Escola Sem Partido certamente 
enfraqueceu seus intentos. Mas o fato é que quando apareceu dinheiro o empresário Miguel Nagib voltou atrás, de algo que parece ter sido mais uma chantagem. 0 plano mais fundo dessa questão é que as ideias defendidas pelo movimento, por mais absurdas que sejam, têm adesão de setores da população, por um lado pela negação do conhecimento e, concomitantemente, pela manipulação moralista. Assim, juntam-se os fundamentalismos político e religioso. Isso significa que o embate continua e o que devemos aprofundar com os professores, pais e alunos é o sentido de uma educação democrática ${ }^{3}$.

JSL: Neste último ano, temos presenciado a defensa enfática do homeschooling, ou "ensino domiciliar". A defesa da proposta se apoia na ideia de que a escola pública tem sido incapaz de garantir um ensino de qualidade. Quais seriam as verdadeiras intenções da proposta? Ela se relaciona com a desconstrução da escola pública? Mas também com a desobrigação do Estado com a educação dos filhos da classe trabalhadora?

GF: Uma das marcas da cultura da classe dominante brasileira é o mimetismo. Uma cultura de associação subordinada ao plano econômico e ao plano cultural, mormente ao que pensa e faz o imperialismo dos Estados Unidos. Hoje se transforma em culto pelo núcleo ideológico do Governo Bolsonaro. 0 movimento de ensino e educação domiciliar, muito em voga nos Estados Unidos, é um exemplo da imitação subdesenvolvida. Um movimento que tem sua defesa em estratos dos grupos mais ricos da classe dominante que une uma formação igualmente ultraindividualista e moralista. Trata-se da formação de seres humanos, como uma espécie de "mamíferos de luxo", protótipos de um laboratório privado que os desprepara para o convívio coletivo. Um movimento, portanto, que vai na contramão do que postula o fundador da sociologia da educação David Émile Durkheim, para o qual a escola tem o papel de arrancar os filhos da vida privada da família para que se socializem dentro da diversidade que se materializa na escola e, como tal, prepará-los para o convívio social.

A sua defesa aqui no Brasil poderia legitimar, também, a ausência histórica do Estado na oferta de educação pública à grande parte da população, mormente o Ensino Médio. 0 intento de oficializar a escola domiciliar entre nós penalizaria duplamente os filhos da classe trabalhadora, pois os pais não teriam em casa as condições objetivas para ensinar e, também, justificaria a não oferta de creches e escolas. Felizmente, a proposta da legalização da escola domiciliar foi negada no Supremo Tribunal Federal, mantendo a obrigatoriedade da escolarização básica.

0 que não apenas os professores, pesquisadores, movimentos sociais, mas todas as forças democráticas do País têm que ter presente é que as teses que disseminam a

\footnotetext{
Os colegas que queiram se aprofundar sobre a ideologia do Movimento Escola Sem Partido e seu antídoto, educação democrática, ver, respectivamente: Frigotto (2017) e Penna, Queiroz e Frigotto (2018).
} 
"nova" ou extrema direita hoje, no Brasil, lembram um passado lúgubre do nazismo e do fascismo e, em nosso meio, reavivam e renovam teses fascistas do movimento integralista, sobretudo nas décadas de 1920 e 1930. Como indica a obra organizada por Natalia dos Reis Cruz (2012), os elementos cultivados por esse movimento eram os da exclusão e intolerância, do apelo ao nacionalismo e à homogeneidade étnico-racial, do moralismo religioso, da defesa da propriedade privada e do combate ao comunismo. Não precisa muito esforço para vermos que o que se reaviva no presente, com a adesão de parte da sociedade, é esse conjunto de antivalores no convívio humano democrático. Aí está a esfinge que necessitamos decifrar e enfrentar para que ela não nos devore. Como intelectuais militantes temos como tarefa inadiável resistir e ajudar os jovens entenderem que é seu futuro que está sendo interditado.

Praia de Intermares, Cabedelo, PB, 3 de setembro de 2019.

\section{REFERÊNCIAS}

BOBBIO, N. Direita e Esquerda - Razões e significados de uma distinção política. São Paulo: Editora Unesp, 1994.

CASTELLS, M. Ruptura. A crise da democracia liberal. Rio de Janeiro: Zahar Editores, 2018.

CRUZ, N. dos R. (org.). Ideias e práticas fascistas no Brasil. Rio de Janeiro: Garamond Universitária, 2012.

FRIGOTTO, G. Escola "sem" Partido: esfinge que ameaça a educação e a sociedade brasileira. Rio de Janeiro: LPP/Uerg, 2017. Disponivel em: http://www.redeuniversitas.com.br/2017/08/download-gratuito-do-livro-escola-sem.html. Acesso em: 29 set. 2019.

HOBSBAWM, E. Tempos fraturados. Cultura e sociedade no século XX. São Paulo: Companhia das Letras, 2013.

KORYBKO, A. Guerras hibridas - das revoluções coloridas aos golpes. São Paulo: Expressão Popular, 2018.

MÉSZÁROS, I. A montanha que devemos conquistar. Reflexões acerca do Estado. São Paulo: Boitempo Editorial, 2015.

PAIXÃO, M. Michael Löwy: Dos governos de direita, Bolsonaro é o que mais tem traços neofascistas. Brasil de Fato, 19 ago. 2019. Disponivel em: https://www.brasildefato.com.br/2019/08/19/michael-lowy-dos-governos-de-direita-bolsonaro-e-o-que-mais-tem-tracos-neofascistas/. Acesso em: 29 set. 2019. 
PENNA, F; QUEIROZ, F; FRIGOTTO, G. Educação democrática - Antídoto ao Escola sem Partido. Rio de Janeiro: LPP/UERJ, 2018. Disponivel em: https://www.eduerj.com/eng/?.product=educacao-democratica-antidoto-ao-escola-sem-partido. Acesso em: 29 set. 2019.

RANCIĖRE, J. 0 ódio à democracia. São Paulo: Boitempo, 2014.

VERISSIMO, L. F. 0 alarme. 0 Estado de S. Paulo, São Paulo, p. 2, 20 fev. 2014. Disponível em: https:// cultura.estadao.com.br/noticias/geral,o-alarme-imp-,1132327. Acesso em: 29 set. 2019.

VERÍSSIMO, L. F. Ódio. 0 Globo, Rio de Janeiro, p. 2, 25 jun. 2015. Disponível em: https://oglobo.globo. com/opiniao/odio-16546533. Acesso em: 29 set. 2019.

WOOD, E. M. Democracia contra o capitalismo: a renovação do materialismo histórico. São Paulo: Boitempo, 2010.

Endereço para correspondência: Cidade Universitária, Campus I, Setor Humanístico, Bloco III, João Pessoa, Paraiba, Brasil; jorgefernandohermida@yahoo.com.br

Roteiro, Joaçaba, U. 45, p. 1-14, jan./dez. 2020 | e23215 |E-ISSN 2177-6059 
